\title{
Paneth cells in diverticular disease of the colon
}

\author{
S. G. SUBBUSWAMY
}

From the Department of Pathology, Newcastle General Hospital, Newcastle upon Tyne

SYNOPSIS Paneth cells were found in the mucosa of the sigmoid colon in 13 out of 27 case $\stackrel{\circ}{3}$ of diverticulosis and diverticulitis. It is concluded that their appearance at this site is a non specific reaction to injury.

Paneth cells are confined, in the adult human intestine, to the crypts of the small intestine and, in much smaller numbers, to the appendix and the proximal half of the colon (Hertzog, 1937; Watson and Roy, 1960; Lauren, 1961). They do not normally occur in the distal colon, but have been described there in ulcerative colitis and in and around benign and malignant tumours (Kerr and Lendrum, 1936; Watson and Roy, 1960; Laurén, 1961; Paterson and Watson, 1961; Gibbs, 1967; Lewin, 1968). It has been suggested that the appearance of Paneth cells is a characteristic response to the specific 'irritation' of ulcerative colitis. Also, as ulcerative colitis is known to predispose to carcinoma, and Paneth cells are known to occur in relation to tumours, Paneth cells might in some way be related to tumour formation. An attempt was therefore made to look for Paneth cells in specimens of colon resected for diverticular disease, a benign condition not known to predispose to malignancy.

\section{Material and Methods}

The material consisted of paraffin blocks from varying sites from 27 specimens of sigmoid colon resected for diverticular disease at the Newcastle General Hospital in the seven years from 1962 to 1968 inclusive.

Sections were stained with haematoxylin and eosin, phloxine-tartrazine, and Mallory's phosphotungstic acid haematoxylin. The latter Received for publication 1 July 1969. stain was found to be particularly good for photography as it gives a strong contrast (Figss 1 and 2).

No attempt was made to examine necropsg material, as such material, due to autolytio change, is unsuitable.

As Paneth cells show a highly irregular distribu衣 tion when they occur in the colon, no attempt was made at precise grading. The cases were merely put into three groups depending on the ease with which Paneth cells could be detecteds

\section{Results}

The mucosa in two cases was severely inflamed and ulcerated making satisfactory examinatio impossible. Paneth cells were found in 13 of the remaining 25 cases. In one case they were numerous, being visible on almost every lowe power field. In a second case, they were present in moderate numbers. In the remaining 11 cases? they could be found only after prolonged searcho

Eleven of the 25 cases showed no evidence of active inflammation, five showed mild chronic ${ }^{+}$ inflammation, four more severe chronic in ${ }^{-}$ flammation, and the remaining five cases acute inflammation. The cases showing Paneth cells were distributed evenly in the different groups $\stackrel{\mathbb{Q}}{\square}$

No relationship could be demonstrated between the presence or absence of Paneth cells and the thickness of the muscular coat.

Paneth cells could be identified definitely in haematoxylin-and-eosin-stained sections in nine cases. In four cases, cells which might have 


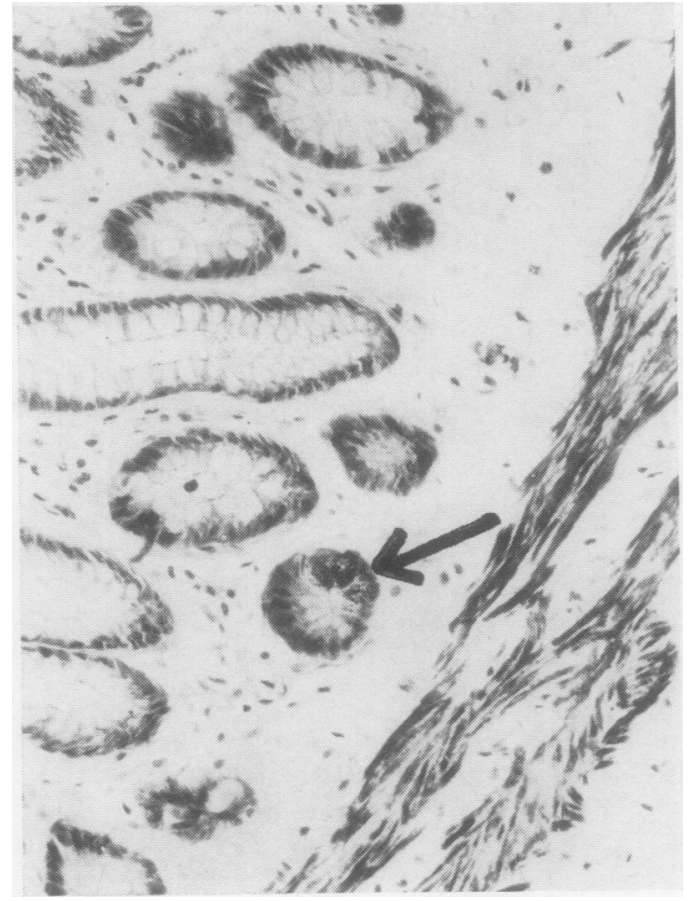

Fig. 1 Paneth cells in the surface mucosa. Mallory's phosphotungstic acid haematoxylin $\times 210$.

been Paneth cells were seen, but could not be definitely identified in such sections, although in two of these Paneth cells could be demonstrated by other stains. In two cases Paneth cells could not be seen in haematoxylin and eosin sections but were shown by other stains. However, in both cases they could be found only after prolonged search, and it appears likely that their detection under the circumstances was due not to the special stains but to the larger number of sections examined. When Paneth cells are not seen in haematoxylin and eosin sections, they are not likely to be demonstrated by other stains, as pointed out by Watson and Roy (1960).

In 12 of the 13 cases in which Paneth cells were found, they were present in the mucosa lining diverticula. In four of these, they were also found in the overlying mucosa lining the lumen of the bowel. In one case they were found only in the overlying mucosa.

\section{Discussion}

Eklöf (1914) suggested that Paneth cells were a non-specific response of the colon to any irritation, a concept with which Lewin (1968)

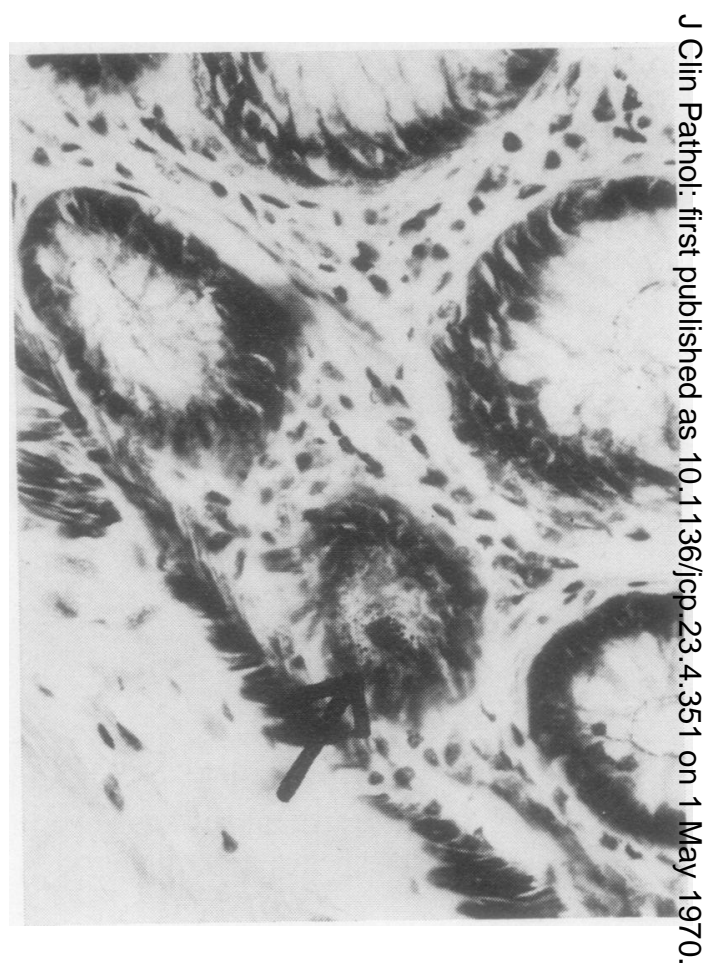

Fig. 2 Paneth cells in the mucosa lining a diverticulum. Mallory's phosphotungstic acid haematoxylin

325.

Both fields shown are from the sigmoid colon of one patient.

is in agreement. Watson and Roy (1960) found no pathological condition other than ulcerative colitis regularly associated with the presence of Paneth cells in the colon and concluded that they? were a characteristic response to that specific irritation.

The finding in the present study of Panetho cells in over half the cases of diverticular disease suggests that it is in fact a non-specific phenome-5 non, and the results agree closely with those obtained by Watson and Roy for sigmoid colons in ulcerative colitis.

The nature of the 'irritation' which may lead to the appearance of Paneth cells in the colon is not clear. In the present series they were not ${ }^{\omega}$ related to inflammatory changes. It is also not clear whether they have any function when theye occur at unusual sites. It has been variously $\mathbb{\Phi}_{\overparen{C}}$ suggested that they might help to protect the ${ }^{-}$ mucosa from malignant change (Black and ${ }^{\circ}$ Ogle, 1948) or from damage by ulcerative colitis (Watson and Roy, 1960). Lewin (1968) con-?

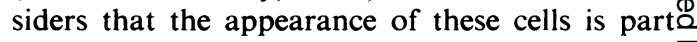
of the mucosal reaction to injury of any sort, and the findings in the present series are in agree- 0 ment.

As Nicholson (1923) pointed out, the prospective potencies of cells are wider than their? prospective values. It is possible that cells with 
the capacity of producing Paneth cells are present throughout the entire colon, but the normal milieu of the distal colon does not favour their appearance although any alteration of the milieu for any reason may favour their appearance. To attribute any specific function to these cells when they occur under such circumstances appears to be teleological.

I am grateful to Dr B. E. Tomlinson for permission to use the material, to Mr M. Stone for his technical assistance, and to Miss D. Kitchener for the photographs.

\section{References}

Black, C. E., and Ogle, R. S. (1948). Influence of local acidiff. cation of tissue bordering cancerous growths. Arch. Path. 46, 107-118.

Eklöf, H. (1914). Chrondriosomenstudien um den Epithel-un Drüsenzellen des Magen-Darmkanals und den Oes phagusdrüsenzellen bei Säugetieren. Anat. Hefte., 51 136. Cited by Watson, A. J., and Roy, A. D. (1960).

Gibbs, N. M. (1967). Incidence and significance of argentatfin and Paneth cells in some tumours of the large intesting J. clin. Path., 20, 826-831.

Hertzog, A. J. (1937). The Paneth cell. Amer. J. Path., 13, 351-36

Kerr, A. B., and Lendrum, A. C. (1936). A chloride-secretiris papilloma in the gall-bladder. Brit. J. Surg., 23, 615-62

Laurén, P. (1961). The cell structure and secretion in intestina cancer with reference to benign epithelial tumours of the bowel. Acta path. microbiol. scand., suppl. 152.

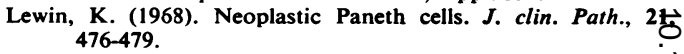

Nicholson, G. W. (1923). Heteromorphoses (metaplasia) of the alimentary tract. J. Path. Bact., 26, 399-417.

Paterson, J. C., and Watson, S. H. (1961). Paneth cell metaplas in ulcerative colitis. Amer. J. Path., 38, 243-249.

Watson, A. J., and Roy, A. D. (1960). Paneth cells in the large intestine in ulcerative colitis. J. Path. Bact., 80, 309-316. 